\title{
PEEP guided by electrical impedance tomography during one-lung ventilation in elderly patients undergoing thoracoscopic surgery
}

\author{
Kun Liu ${ }^{1}$, Chengya Huang ${ }^{1}$, Meiying $\mathrm{Xu}^{1}$, Jingxiang $\mathrm{Wu}^{1}$, Inez Frerichs ${ }^{2}$, Knut Moeller ${ }^{3}$, Zhanqi Zhao ${ }^{3,4}$ \\ ${ }^{1}$ Department of Anesthesiology, Shanghai Chest Hospital, Shanghai Jiao Tong University, Shanghai 200030, China; ${ }^{2}$ Department of Anesthesiology \\ and Intensive Care Medicine, University Medical Center of Schleswig-Holstein, Campus Kiel, Germany; ${ }^{3}$ Institute of Technical Medicine, Furtwangen \\ University, Villingen-Schwenningen, Germany; ${ }^{4}$ Department of Biomedical Engineering, Fourth Military Medical University, Xi'an 710000 , China \\ Contributions: (I) Conception and design: J Wu, M Xu, Z Zhao; (II) Administrative support: None; (III) Provision of study materials or patients: \\ None; (IV) Collection and assembly of data: K Liu, C Huang; (V) Data analysis and interpretation: J Wu, K Liu, I Frerichs, K Moeller, Z Zhao; \\ (VI) Manuscript writing: All authors; (VII) Final approval of manuscript: All authors. \\ Correspondence to: Jingxiang Wu, MD. Department of Anesthesiology, Shanghai Chest Hospital, Shanghai Jiao Tong University, No. 241 Huaihai Rd. \\ West, Shanghai 200030, China. Email: wu_jingxiang@sjtu.edu.cn.
}

Background: To examine the influence of positive end-expiratory pressure (PEEP) settings on lung mechanics and oxygenation in elderly patients undergoing thoracoscopic surgery.

Methods: One hundred patients aged $>65$ years were randomly allocated into either the $\mathrm{PEEP}_{5}$ or the electrical impedance tomography (EIT) group $\left(\mathrm{PEEP}_{\mathrm{EIT}}\right)$. Each group underwent volume-controlled ventilation (tidal volume $6 \mathrm{~mL} / \mathrm{kg}$ predicted body weight) with the PEEP either fixed at $5 \mathrm{cmH}_{2} \mathrm{O}$ or set at an individualized EIT setting. The primary endpoint was the ratio of the arterial oxygen partial pressure to the fractional inspired oxygen $\left(\mathrm{PaO}_{2} / \mathrm{FiO}_{2}\right)$. The secondary endpoints included the driving pressure, and dynamic respiratory system compliance $\left(\mathrm{C}_{\mathrm{dyn}}\right)$. Other outcomes, such as the mean airway pressure $\left(\mathrm{P}_{\text {mean }}\right)$, mean arterial pressure (MAP), lung complications and the length of hospital stay were explored.

Results: The optimal PEEP set by EIT was significantly higher (range from 9-13 $\mathrm{cmH}_{2} \mathrm{O}$ ) than the fixed PEEP. $\mathrm{PaO}_{2} / \mathrm{FiO}_{2}$ was $47 \mathrm{mmHg}$ higher (95\% CI: 7-86 mmHg; $\mathrm{P}=0.021$ ), $\mathrm{C}_{\mathrm{dyn}}$ was $4.3 \mathrm{~mL} / \mathrm{cmH}_{2} \mathrm{O}$ higher (95\% CI: 2.1-6.7 $\left.\mathrm{cmH}_{2} \mathrm{O} ; \mathrm{P}<0.001\right)$, and the driving pressure was $3.7 \mathrm{cmH}_{2} \mathrm{O}$ lower $\left(95 \% \mathrm{CI}: 2.2-5.1 \mathrm{mmH}_{2} \mathrm{O}\right.$; $\mathrm{P}<0.001)$ at $0.5 \mathrm{~h}$ during one-lung ventilation $(\mathrm{OLV})$ in the $\mathrm{PEEP}_{\mathrm{EIT}}$ group than in the $\mathrm{PEEP}_{5}$ group. At $1 \mathrm{~h}$ during $\mathrm{OLV}, \mathrm{PaO}_{2} / \mathrm{FiO}_{2}$ was $93 \mathrm{mmHg}$ higher (95\% CI: 58-128 mmHg; $\mathrm{P}<0.001$ ), $\mathrm{C}_{\text {dyn }}$ was $4.4 \mathrm{~mL} / \mathrm{cmH}_{2} \mathrm{O}$ higher (95\% CI: $1.9-6.9 \mathrm{~mL} / \mathrm{cmH}_{2} \mathrm{O} ; \mathrm{P}=0.001$ ), and the driving pressure was $4.9 \mathrm{cmH}_{2} \mathrm{O}$ lower (95\% CI: 3.8-6.1 $\left.\mathrm{cmH}_{2} \mathrm{O} ; \mathrm{P}<0.001\right)$ in the $\mathrm{PEEP}_{\mathrm{EIT}}$ group than in the $\mathrm{PEEP}_{5}$ group. $\mathrm{PaO}_{2} / \mathrm{FiO}_{2}$ was $107 \mathrm{mmHg}$ higher (95\% CI: 56-158 mmHg; $\mathrm{P}<0.001$ ) in the $\mathrm{PEEP}_{\mathrm{EIT}}$ group than in the $\mathrm{PEEP}_{5}$ group during double-lung ventilation at the end of surgery.

Conclusions: PEEP values determined with EIT effectively improved oxygenation and lung mechanics during one lung ventilation in elderly patients undergoing thoracoscopic surgery.

Keywords: Elderly patients; electrical impedance tomography (EIT); one-lung ventilation; positive end-expiratory pressure level; lung-protective ventilation

Submitted Aug 14, 2019. Accepted for publication Nov 05, 2019.

doi: $10.21037 /$ atm.2019.11.95

View this article at: http://dx.doi.org/10.21037/atm.2019.11.95 


\section{Introduction}

Elderly patients often develop pulmonary dysfunction, which is associated with a high risk for thoracic surgery (1). Age has been reported to be one of the independent risk factors for major pulmonary complications and to be associated with poor long-term outcomes after thoracic surgery (2). Although the video-assisted thoracic surgery approach has reduced pulmonary complications from $45 \%$ to $28 \%$ compared with thoracotomy in elderly patients (3), the incidence of complications is reported to be $7.3-13 \%$, which is relatively higher than the average reported incidence $(2,4-6)$. Intraoperative anaesthesia and ventilation management may be critical for reducing postoperative pulmonary complications (7-9).

A previous study indicated that the implementation of a lung protective ventilation (LPV) strategy during one-lung ventilation (OLV) can improve the prognosis of elderly patients (10). At present, the commonly used LPV strategy involves the use of lung recruitment manoeuvres, a small tidal volume $\left(\mathrm{V}_{\mathrm{T}}\right)(6-8 \mathrm{~mL} / \mathrm{kg}$ ideal body weight), and certain levels of positive end-expiratory pressure (PEEP) (11). Although a small $\mathrm{V}_{\mathrm{T}}$ is an important component of an LPV strategy for surgical patients during OLV, without an adequate level of PEEP, it does not prevent postoperative respiratory complications (12). We speculate that the most likely reason for this issue is that reducing the $V_{T}$ inevitably increases the risk for atelectasis, and it is necessary to keep the lungs open with an appropriate PEEP. In other words, we need to find a balance between hyperinflation and atelectasis. Given that the closing capacity commonly exceeds the functional residual capacity (FRC) in older patients it can be assumed that a substantial portion of the ventilation during small $\mathrm{V}_{\mathrm{T}}$ OLV occurs below the closing capacity unless active measures to restore the end-expiratory lung volume are taken. Therefore, the PEEP setting is important for older patients. However, how to optimize the PEEP setting during OLV remains a controversial topic, and whether a fixed PEEP value is suitable for all patients, especially in the elderly patients during OLV, is unclear.

Electrical impedance tomography (EIT) is a medical imaging method that allows the reconstruction of dynamic pulmonary images; safe electrical signals are applied to the human body, and the changes in chest conductivity caused by the changes in lung gas distributions are measured (13). It can be used to monitor pulmonary ventilation in real time and guide the selection of individualized ventilation parameters (14). A recent study reported that EIT can be used for selecting individualized PEEP settings to optimize intraoperative mechanical ventilation, to improve intraoperative oxygenation and to reduce postoperative atelectasis in abdominal surgery (9). Nestler et al. also reported that an individualized high PEEP titrated by EIT can restore end-expiratory lung volume and improve regional ventilation distribution and oxygenation during anaesthesia in obese patients undergoing elective laparoscopic surgery (15). In these studies, the approach based on regional compliance proposed by Costa $e t$ al. was often used for bedside PEEP titration (16). Our previous study also revealed that it was feasible to titrate the PEEP at the bedside during OLV using EIT in combination with $\mathrm{PaO}_{2}$ (17). We hypothesize that individualized PEEP values titrated by EIT can improve ventilation and respiratory mechanics in elderly patients undergoing thoracoscopic surgery during OLV.

The aim of this study was to examine whether the PEEP value set based on EIT can improve respiratory mechanics and oxygenation compared to a fixed PEEP of $5 \mathrm{cmH}_{2} \mathrm{O}$ in elderly patients during thoracoscopic ventilation.

\section{Methods}

This study was approved by the Ethics committee of the Shanghai Chest Hospital (Chair: Dr. Zheng Ning, permission NO. KS1866) on Sep-18-2018, and all patients signed written informed consent forms before enrolment. The trial was registered in the Chinese Clinical Trial Registry (www.chictr.org.cn/, registry number: ChiCTR1900021119) on Jan-29-2019.

\section{Selection and description of the participants}

Consecutive patients older than 65 years scheduled for thoracoscopic pneumonectomy were included in the study from Jan-30-2019 to May-14-2019. The inclusion criteria were as follows: (I) was scheduled for thoracoscopic lung surgery; (II) needed OLV during operation; (III) was expected to need postoperative hospitalization for at least 2 days; (IV) was diagnosed with an American Association of Anaesthesiologists (ASA) score of II or III; and (V) had a complete pulmonary function examination report available before the operation. The exclusion criteria were as follows: (I) poor lung function (i.e., suspected OLV intolerance); (II) preoperative bronchiectasis, respiratory infection, persistent cough and large sputum volumes (>100 mL/day); (III) 
any contraindications to the use of EIT (e.g., pacemaker, automatic implantable defibrillator, implantable pump); (IV) preoperative haemodynamic instability; and (V) suspected PEEP titration intolerance.

The patients were randomly allocated into one of two groups, the $\mathrm{PEEP}_{5}$ or $\mathrm{PEEP}_{\mathrm{EIT}}$ group, using simple randomization, yielding a 1:1 ratio of patients in each group. The randomization sequence was generated by staff members not involved in the current study. The sequence was concealed using sealed opaque envelopes.

\section{Technical information}

Anaesthesia was induced with target-controlled infusion of propofol $\left(4.0 \mu \mathrm{g} \cdot \mathrm{mL}^{-1}\right)$, sufentanil $\left(0.5 \mu \mathrm{g} \cdot \mathrm{kg}^{-1}\right)$ and cisatracurium $\left(0.2 \mathrm{mg} \cdot \mathrm{kg}^{-1}\right)$. The muscle relaxation levels were closely and automatically monitored by an acceleromyograph (TOF-watch-SX, MSD BV, Oss, the Netherlands), and neuromuscular transmission was continuously monitored every 15 seconds. Anaesthesia were maintained with $2.0-3.0 \mu \mathrm{g} \cdot \mathrm{mL}^{-1}$ propofol target infusion, remifentanil $0.1 \mu \mathrm{g} \cdot \mathrm{kg}^{-1} \cdot \mathrm{min}^{-1}$ and cisatracurium $0.12 \mathrm{mg} \cdot \mathrm{kg}^{-1} \cdot \mathrm{h}^{-1}$ and adjusted by the anaesthesiologist according to his or her clinical experience. After the anaesthesia and muscle relaxation stages were completed, a double-lumen endobronchial tube (Shiley ${ }^{\mathrm{TM}} 35$ or 37 French, Covidien, Mansfield, MA) was inserted with a visual laryngoscope and a fiberoptic bronchoscopy to ensure the correct position of the tube. Double-lung mechanical ventilation (DLV) (Primus, Dräger Medical, Lübeck, Germany) was applied with a $V_{\mathrm{T}}$ of $8 \mathrm{~mL} \cdot \mathrm{kg}^{-1}$ ideal body weight, an inhaled fraction of oxygen $\left(\mathrm{FiO}_{2}\right)$ of 1.0, an inspiration-to-expiration time (I:E) ratio of 1:2, a ventilation frequency of 15 breaths. $\mathrm{min}^{-1}$ and a PEEP of $5 \mathrm{cmH}_{2} \mathrm{O}$. All patients were in the lateral position required for surgery. During OLV, the $\mathrm{V}_{\mathrm{T}}$ was adjusted to $6 \mathrm{~mL} \cdot \mathrm{kg}^{-1}$ ideal body weight. The PEEP level was set to either $5 \mathrm{cmH}_{2} \mathrm{O}\left(\mathrm{PEEP}_{5}\right.$ group) or an individualized

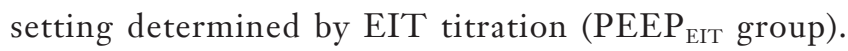
An insulation blanket kept the patients' nasopharyngeal temperature above $36^{\circ} \mathrm{C}$. After surgery, the double lumen tube was not changed, the patients were switched to DLV, and then the two-lung recruitment manoeuvre (pressure held at $35 \mathrm{cmH}_{2} \mathrm{O}$ for 15 seconds) was performed for lung re-expansion after the two drainage tubes (apical and basal tubes) were placed and the chest was closed. None of the patients used $\mathrm{CO}_{2}$ pneumothorax. The DLV mode was maintained until patients extubated in the recovery room. The ventilator parameters were as follows: VT of $8 \mathrm{~mL} \cdot \mathrm{kg}^{-1}, \mathrm{FiO}_{2}$ of 0.6 and PEEP of $5 \mathrm{cmH}_{2} \mathrm{O}$. All other ventilator parameters remained unchanged during the study. The duration of this DLV period was $30-40 \mathrm{~min}$. After the operation, all the patients were transferred to the recovery room (post-anaesthesia care unit, PACU) for extubation. The PACU was near the operation room area and under the charge of a senior anaesthesiologist. The patients were managed under the ERAS guidelines and extubated within $30 \mathrm{~min}$ after surgery.

Individual PEEP titration in the EIT group was performed as follows. A 40-mm EIT electrode belt, which carries 16 electrodes, was placed around the thorax in the fifth intercostal space, and one reference electrode was placed at the patients' abdomen (PulmoVista 500, Draeger Medical, Luebeck, Germany). EIT images were continuously recorded at $20 \mathrm{~Hz}$ and reconstructed with the baseline referring to the lowest impedance value measured before the PEEP titration started. The data were filtered using a Butterworth $4^{\text {th }}$ degree low-pass filter with a cutoff frequency of $50 / \mathrm{min}$ to eliminate impedance changes synchronous with the heart rate. After the manual lung recruitment manoeuvre (pressure held at $35 \mathrm{cmH}_{2} \mathrm{O}$ for 15 seconds each) was performed twice, a decremental PEEP trial was performed from 15 to $1 \mathrm{cmH}_{2} \mathrm{O}$ with increments of $2 \mathrm{cmH}_{2} \mathrm{O}$, and each level was held for one minute each (with deviations of up to 5 seconds). EIT data analysis was achieved with customized software. Regional respiratory system compliance was computed in all pixels in the lung regions at each PEEP level. Then, cumulated collapse and overdistension percentages were estimated based on the change in the regional compliance curve during decremental PEEP titration, either towards lower or higher PEEP levels (16). The PEEP level selected for the patients in the EIT group was the intercept point of the cumulated collapse and overdistension percentages curves, providing the compromise between the collapsed and overdistended lung (Figure 1).

Baseline demographics, such as sex, age, body mass index, history of hypertension and diabetes, smoking history, drinking history, pulmonary function examination results, infusion volume and operation time were recorded. The primary endpoint was the ratio of the arterial oxygen partial pressure to the fractional inspired oxygen $\left(\mathrm{PaO}_{2} / \mathrm{FiO}_{2}\right)$ at the following time points: (I) during DLV after anaesthesia, (II) during OLV at $0.5 \mathrm{~h}$, (III) during OLV at $1 \mathrm{~h}$ after the operation start, and (IV) during DLV at the end of the operation in the operating room. 
A
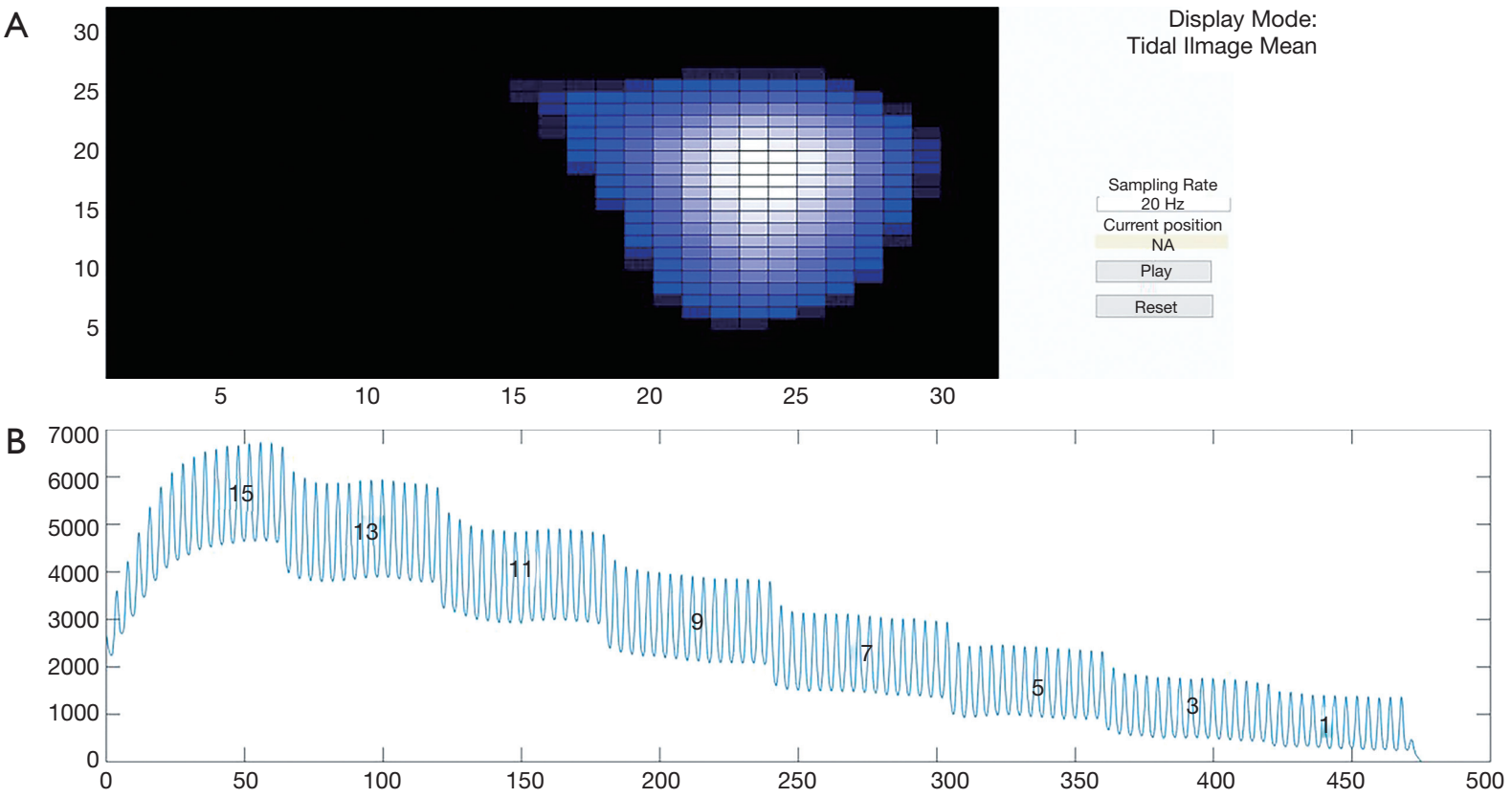

C

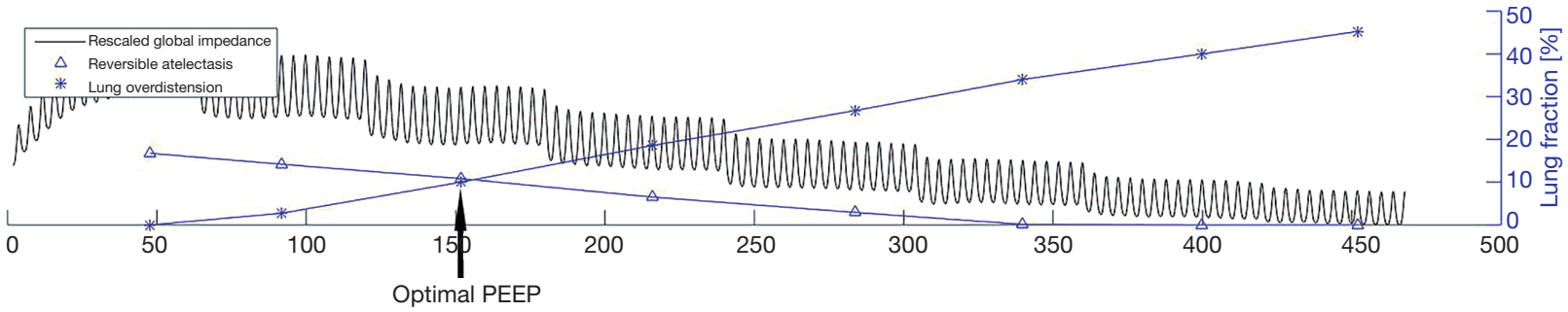

Figure 1 Individual PEEP titration method using lung electrical impedance tomography (EIT). (A) Mean tidal volume image of one-

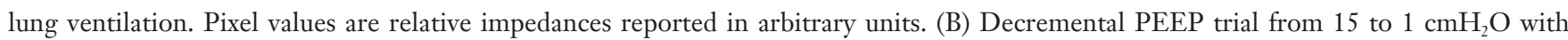
increments of $2 \mathrm{cmH}_{2} \mathrm{O}$ and a duration of one minute at each level. (C) The intercept point of the cumulated collapse and overdistension percentage curves (black arrow) is the optimal PEEP.

The secondary endpoints included the driving pressure and dynamic respiratory system compliance $\left(\mathrm{C}_{\mathrm{dyn}}\right)$ at various time points. Other outcomes that were collected and compared included the peak airway pressure $\left(\mathrm{P}_{\text {peak }}\right)$, plateau pressure $\left(\mathrm{P}_{\text {plat }}\right)$, mean airway pressure $\left(\mathrm{P}_{\text {mean }}\right)$, mean arterial pressure (MAP), vasopressin drug dosage, partial pressure of carbon dioxide $\left(\mathrm{PaCO}_{2}\right), \mathrm{PH}$, postoperative pulmonary complications, and length of hospital stay. The following pulmonary complications during postoperative hospitalization were included: (I) atelectasis detected on CT scans or chest radiographs; (II) pneumonia diagnosed according to the Centers for Disease Control standards (18) or aspiration pneumonia; (III) acute respiratory distress syndrome diagnosed according to the Berlin definition (19); (IV) stump leakage, chest drainage for more than 5 days;
(V) bronchopleural fistula; (VI) ventilation support for more than $48 \mathrm{~h}$; (VII) re-tracheal intubation; (VIII) empyema; (IX) respiratory failure; $(\mathrm{X})$ pulmonary embolism; and $(\mathrm{XI})$ pleural effusion. Subgroup analyses were carried out to determine the changes in respiratory mechanics and $\mathrm{PaO}_{2} / \mathrm{FiO}_{2}$ in patients with normal or poor preoperative lung function and the side effects of OLV under different PEEP levels. Patients with poor lung function were defined as those with MVV \% or $\mathrm{FEV} 1 \%<70 \%$ of the predicted value, and the different sides were compared in single lung ventilation.

\section{Statistics}

According to our unpublished preliminary experiment that included 5 patients in each group, the use of individualized 


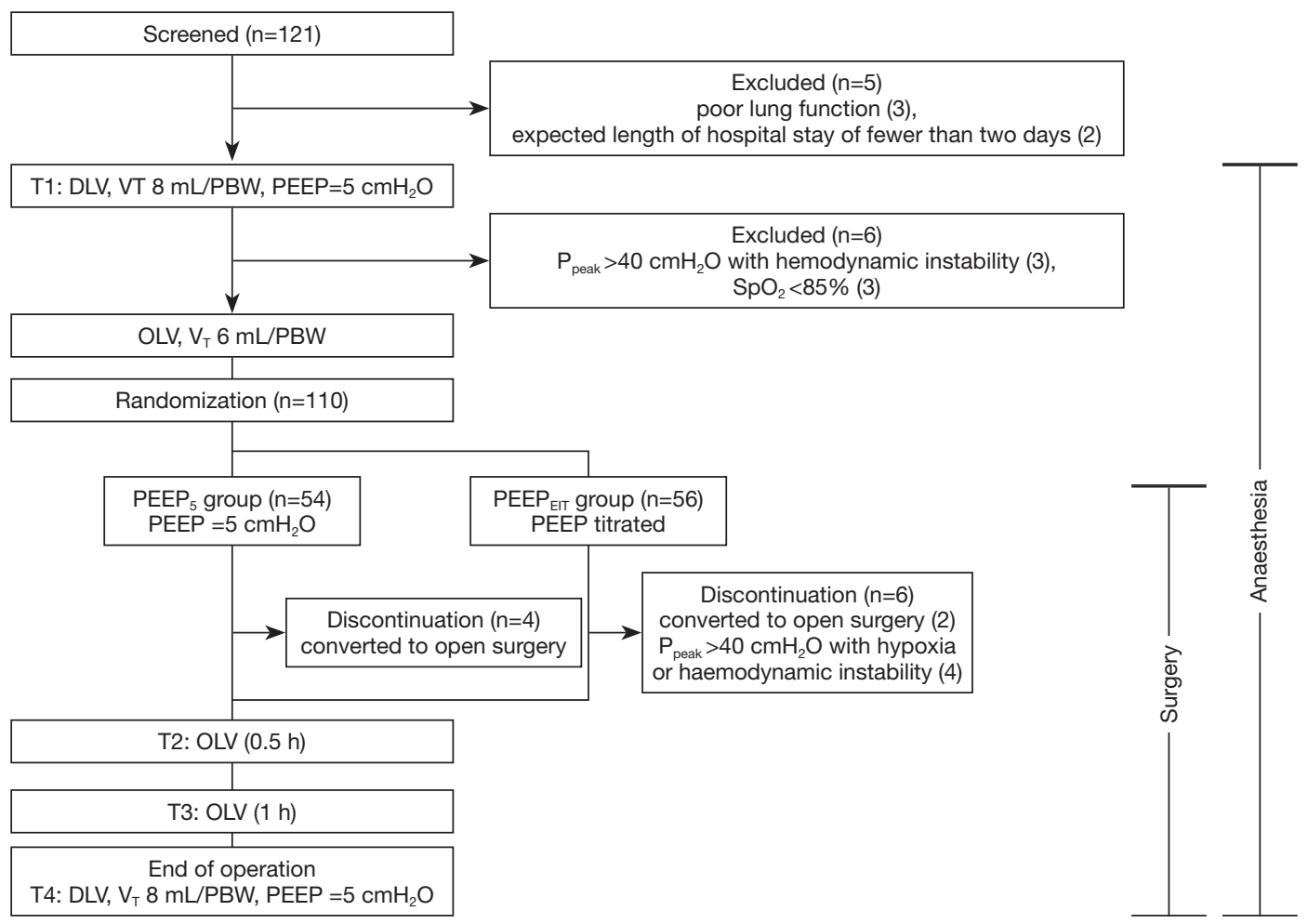

Figure 2 Workflow of the thoracoscopic surgery protocol applied in aged patients from both groups. $\mathrm{P}_{\text {peak }}$, peak pressure; $\mathrm{SpO}_{2}$, peripheral capillary oxygen saturation; $\mathrm{PEEP}_{\text {ind }}$, electrical impedance tomography-based individualized $\mathrm{PEEP}_{2} \mathrm{PEEP}_{5}$, a fixed $\mathrm{PEEP}_{\text {of }} 5$ cmH $\mathrm{C}_{2}$ PEEP; PBW, predicted body weight; DLV, two-lung ventilation; OLV, one-lung ventilation; VCV, volume-controlled ventilation; VT, tidal volume; RR, respiratory rate; I:E, inspiration to expiration time.

PEEP titration can increase $\mathrm{PaO}_{2} / \mathrm{FiO}_{2}$ by $20 \%$. Thus, we set $\alpha=0.05,1-\beta=0.8$, and the ratio of members in each group to be 1:1 and estimated the sample size using $G^{*}$ power software (version 3.1.9.2; Franz Faul, Universitat Kiel, Germany) and the F-test in repeated measures analysis of variance; the recommended sample size was 82 . Considering the exploratory nature of this study, possible drop-outs and the variation of the group differences, the sample size was set to be 100 . Statistical analysis was performed using SPSS (version 23; IBM Corp. Armonk, NY, USA). The mean \pm standard deviation was used where applicable. The $\mathrm{PaO}_{2} / \mathrm{FiO}_{2}, \mathrm{C}_{\text {dyn }}$, driving pressure and intragroup comparisons were analysed by the general linear model of two-way repeated measures ANOVA, followed by Tukey's HSD post-hoc test for multiple comparisons. The ASA classification and modus operandi were compared by the chi-squared test. The respiratory mechanics and arterial blood gasses between the two groups were tested by the independent samples $t$ test. When the data were not normally distributed, the rank-sum test was used instead of the $t$ test. $\mathrm{P}<0.05$ was considered statistically significant. The significance levels were corrected where applicable for multiple comparisons using Holm's sequential Bonferroni method.

\section{Results}

One hundred and twenty-one patients were screened. The complete flow diagram is given in Figure 2. Eleven patients were excluded due to poor lung function $(n=3)$, expected length of hospital stay of fewer than two days $(\mathrm{n}=2), \mathrm{P}_{\text {peak }}>$ $40 \mathrm{cmH}_{2} \mathrm{O}$ with haemodynamic instability $(\mathrm{n}=3)$ or $\mathrm{SpO}_{2}$ $<85 \%(n=3)$. In total one hundred ten patients were randomly allocated into the two groups (54 in $\mathrm{PEEP}_{5}$ and 56 in the PEEP EIT $_{\text {group). The study protocol was }}$ successfully completed in one hundred patients (50 in

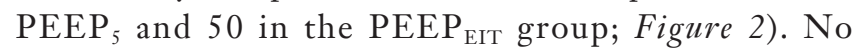
significant differences were found terms of sex, age, body mass index, ASA classification, pulmonary function, infusion volume or operation time between the two groups at 
Table 1 Baseline demographics and comparison between the two study groups

\begin{tabular}{|c|c|c|}
\hline Characteristic & PEEP $_{5}(n=50)$ & PEEP $_{\text {EIT }}(n=50)$ \\
\hline $\operatorname{Sex}(M / F)$ & $21 / 29$ & $23 / 27$ \\
\hline Age (years) & $69.0 \pm 3.3$ & $70.2 \pm 4.3$ \\
\hline BMI $\left(\mathrm{kg} \cdot \mathrm{m}^{-2}\right)$ & $23.2 \pm 3.1$ & $24.3 \pm 4.5$ \\
\hline ASA classification (II/III) & $39 / 11$ & $39 / 11$ \\
\hline Smokes (yes/no) & $12 / 38$ & $9 / 41$ \\
\hline Drinks alcohol (yes/no) & $7 / 43$ & $2 / 48$ \\
\hline Hypertension (yes/no) & $14 / 36$ & $17 / 33$ \\
\hline Diabetes (yes/no) & $5 / 45$ & $3 / 47$ \\
\hline MVV (\%predicted) & $115.6 \pm 22.5$ & $118.3 \pm 30.5$ \\
\hline $\mathrm{FEV}_{1}$ (\% predicted) & $86.5 \pm 14.2$ & $92.2 \pm 18.7$ \\
\hline Transfusion volume $(\mathrm{mL})$ & $1,290 \pm 422$ & $1,241 \pm 416$ \\
\hline Operation time (min) & $93 \pm 41$ & $87 \pm 54$ \\
\hline \multicolumn{3}{|l|}{ Procedure } \\
\hline Pneumonectomy & 1 & 0 \\
\hline Wedge resection & 12 & 9 \\
\hline Lobectomy & 30 & 37 \\
\hline Wedge + lobectomy & 7 & 4 \\
\hline
\end{tabular}

M, male; F, female; BMI, body mass index; MVV \%predicted, ratio of measured value to theoretical predicted value of maximal ventilatory volume; $\mathrm{FEV}_{1}$, forced expiratory volume in 1 second.

baseline (Table 1).

During OLV, the individualized PEEP titrated with EIT ranged from 9 to $13 \mathrm{cmH}_{2} \mathrm{O}(10.8 \pm 1.8)$, which was significantly higher than the PEEP value applied in the control group $\left(5 \mathrm{cmH}_{2} \mathrm{O}, \mathrm{P}<0.01\right)$.

$\mathrm{PaO}_{2} / \mathrm{FiO}_{2}$ decreased in both groups during OLV compared with DLV $(\mathrm{P}<0.001) . \mathrm{PaO}_{2} / \mathrm{FiO}_{2}$ in the EIT group was $47 \mathrm{mmHg}$ higher at $0.5 \mathrm{~h}$ (95\% CI: 7-86 mmHg; $\mathrm{P}=0.021), 93 \mathrm{mmHg}$ higher at $1 \mathrm{~h}$ (95\% CI: 58-128 $\mathrm{mmHg}$; $\mathrm{P}<0.001)$ during $\mathrm{OLV}$, and $107 \mathrm{mmHg}$ higher at the end of the operation (95\% CI: 56-158 mmHg; $\mathrm{P}<0.001$ ) compared with that in the control group (Figure $3 A$ ).

The driving pressure was $3.7 \mathrm{cmH}_{2} \mathrm{O}$ lower at $0.5 \mathrm{~h}$ (95\% CI: $2.2-5.1 \mathrm{mmH}_{2} \mathrm{O} ; \mathrm{P}<0.001$ ) and $4.9 \mathrm{cmH}_{2} \mathrm{O}$ lower at $1 \mathrm{~h}\left(95 \%\right.$ CI: $\left.3.8-6.1 \mathrm{cmH}_{2} \mathrm{O} ; \mathrm{P}<0.001\right)$ during $\mathrm{OLV}$ in the EIT group than in the control group, but there was no significant difference at the end of the operation between the control and EIT groups (Figure 3B).
$\mathrm{C}_{\text {dyn }}$ was $4.3 \mathrm{~mL} / \mathrm{cmH}_{2} \mathrm{O}$ higher in the EIT group than in the control group at $0.5 \mathrm{~h}\left(95 \% \mathrm{CI}: 2.1-6.7 \mathrm{~mL} / \mathrm{cmH}_{2} \mathrm{O}\right.$; $\mathrm{P}<0.001)$, and $4.4 \mathrm{~mL} / \mathrm{cmH}_{2} \mathrm{O}$ higher at $1 \mathrm{~h}$ (95\% CI: 1.9 $6.9 \mathrm{~mL} / \mathrm{cmH}_{2} \mathrm{O} ; \mathrm{P}=0.001$ ) during $\mathrm{OLV}$ (Figure 3 C).

The subgroup analysis revealed a similar trend compared to the primary results in Figure 3. The results were descriptively analysed due to the significant imbalance in the number of subgroups (Tables 2,3).

Compared to the $\mathrm{PEEP}_{5}$ group, the $\mathrm{PEEP}_{\mathrm{EIT}}$ group had significantly higher $\mathrm{P}_{\text {peak }}, \mathrm{P}_{\text {mean }}$ and $\mathrm{P}_{\text {plat }}$ values during OLV after 0.5 and 1 h. $\mathrm{pH}$ and $\mathrm{PCO}_{2}$ showed significant difference between the groups only at the end of operation $(\mathrm{P}<0.05$; Table 4).

No significant differences were found in the use of vasoactive drugs, lung complications or duration of hospitalization between the two groups (Table 5).

\section{Discussion}

In this study, EIT was used to titrate PEEP during OLV in elderly patients undergoing thoracoscopic surgery and the outcomes were compared to a fixed PEEP of $5 \mathrm{cmH}_{2} \mathrm{O}$ during surgery. Ventilation with individualized PEEP can significantly improve $\mathrm{PaO}_{2} / \mathrm{FiO}_{2}$, the driving pressure and $\mathrm{C}_{\mathrm{dyn}}$, but not the incidence of pulmonary complications or the length of hospital stay after surgery. The results of our study show that the optimal PEEP can be set by EIT and effectively improve lung mechanics during the operation in this patient population.

A suitable combination of a PEEP with low $V_{T}$ has been indicated to reduce the mechanical ventilation pressure, prevent acute lung injuries, and play a protective role in lung ventilation (20). It is one of the effective measures that may reduce postoperative complications. However, the optimal level of PEEP depends on the patient's individual status, body mass index and posture. It is questionable whether the same fixed PEEP value can meet the individual needs of all patients. Leong et al. compared high and low PEEP settings in patients with open-chest OLV (21). They found no significant differences in the $\mathrm{C}_{\mathrm{dyn}}$ and oxygenation index. We suspect that the PEEP used in that study was not individually titrated or optimal.

Previous approaches used to identify individualized PEEP settings include the identification of the pressure obtained at the low inflection point $\left(\right.$ or $\left.+2 \mathrm{cmH}_{2} \mathrm{O}\right)$ of the static pressure-volume curve and the value corresponding to the best oxygenation level or $\mathrm{C}_{\mathrm{dyn}}$. The generation of a static pressure-volume curve requires an interruption of normal 

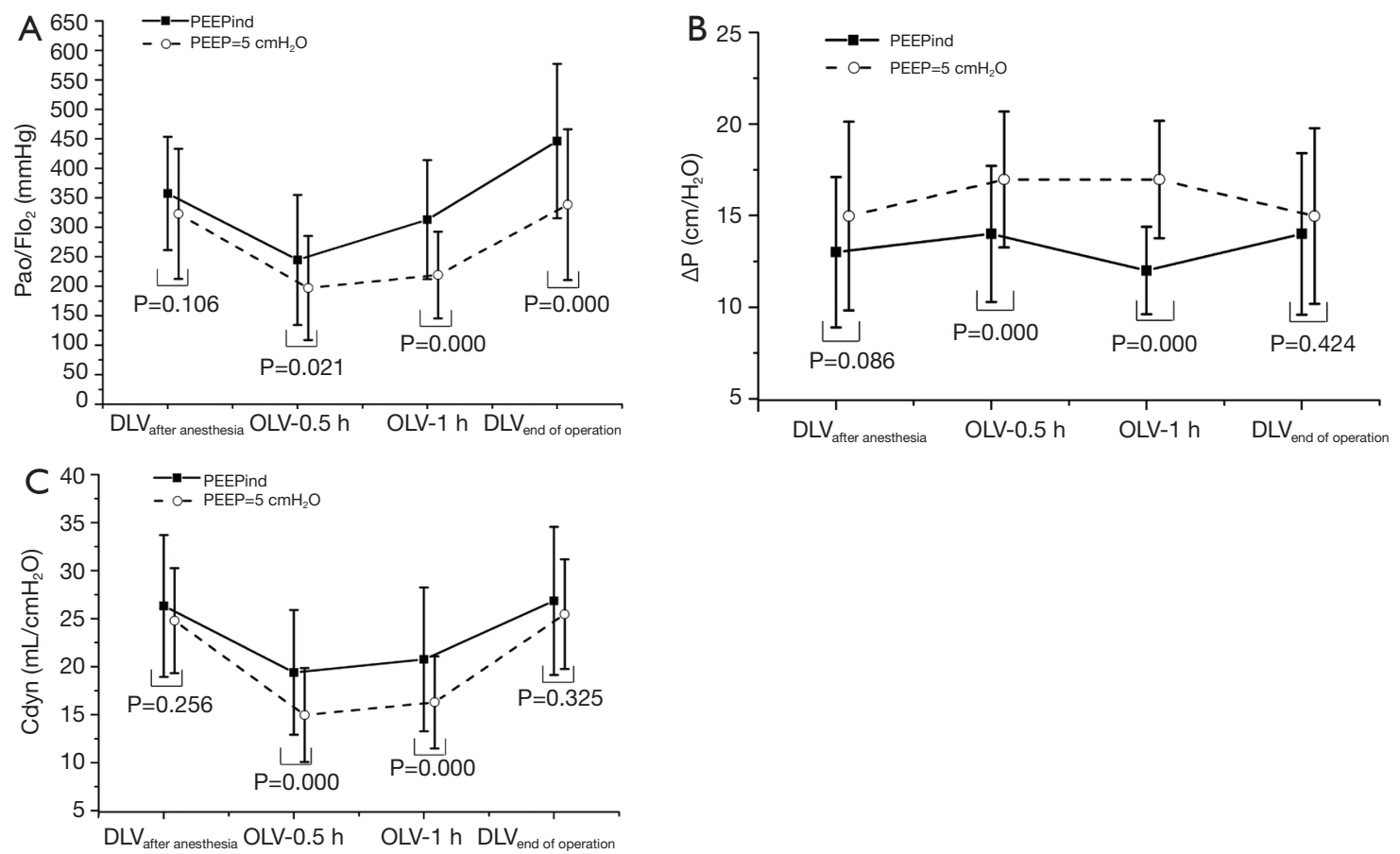

Figure 3 Comparison of $\mathrm{PaO}_{2} / \mathrm{FiO}_{2}$ (A), driving pressure (B) and pulmonary dynamic compliance (C) between the two study groups at different time points. $\mathrm{PaO}_{2}$, partial pressure of oxygen in arterial blood; $\mathrm{FiO}_{2}$, fraction of inspired oxygen; $\Delta \mathrm{P}$, driving pressure; $\mathrm{C}_{\mathrm{dyn}}$,

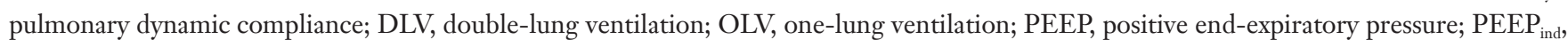
individual PEEP determined with EIT; *, significant difference compared to the control group, $\mathrm{P}<0.05$.

Table 2 Subgroup analyses of the changes in respiratory mechanics and $\mathrm{PaO}_{2} / \mathrm{FiO}_{2}$ in patients with normal or poor preoperative lung function under different PEEP levels

\begin{tabular}{|c|c|c|c|c|c|c|}
\hline Lung function & Group & $n$ & DLV & OLV $0.5 \mathrm{~h}$ & OLV $1 \mathrm{~h}$ & DLV- ${ }_{\text {End of operation }}$ \\
\hline \multicolumn{7}{|l|}{$\mathrm{PaO}_{2} / \mathrm{FiO}_{2}$} \\
\hline Normal & PEEP $_{5}$ & 44 & $340.4 \pm 92.1$ & $189.9 \pm 74.5$ & $215.4 \pm 59.5$ & $333.0 \pm 118.5$ \\
\hline \multirow[t]{2}{*}{ Poor } & PEEP $_{5}$ & 6 & $299.8 \pm 79.1$ & $139.3 \pm 74.7$ & $167.9 \pm 72.8$ & $385.2 \pm 189.7$ \\
\hline & PEEP $P_{E I T}$ & 5 & $350.2 \pm 67.0$ & $220.9 \pm 119.5$ & $277.6 \pm 87.5^{\mathrm{b}}$ & $453.8 \pm 117.7$ \\
\hline \multirow[t]{2}{*}{ Normal } & PEEP $_{5}$ & 44 & $24.8 \pm 5.5$ & $14.8 \pm 5.0$ & $16.0 \pm 4.7$ & $25.3 \pm 5.8$ \\
\hline & PEEP $_{\text {EIT }}$ & 45 & $26.8 \pm 7.2$ & $19.4 \pm 6.7^{\mathrm{a}}$ & $21.1 \pm 7.6^{a}$ & $27.4 \pm 7.7$ \\
\hline \multirow[t]{2}{*}{ Poor } & PEEP $_{5}$ & 6 & $25.4 \pm 5.7$ & $12.9 \pm 5.4$ & $18.8 \pm 5.1$ & $26.5 \pm 5.4$ \\
\hline & PEEP $P_{E I T}$ & 5 & $23.7 \pm 6.6$ & $18.9 \pm 4.8^{b}$ & $20.3 \pm 4.9$ & $26.2 \pm 4.3$ \\
\hline \multicolumn{7}{|l|}{$\Delta \mathrm{P}$} \\
\hline \multirow[t]{2}{*}{ Poor } & PEEP $_{5}$ & 6 & $14.7 \pm 4.5$ & $17.7 \pm 6.3$ & $17.5 \pm 6.0$ & $15.3 \pm 3.1$ \\
\hline & PEEP & 5 & $16.0 \pm 2.8$ & $14.0 \pm 2.2^{b}$ & $13.1 \pm 4.2^{b}$ & $15.3 \pm 3.3$ \\
\hline
\end{tabular}

Poor lung function was defined as MVV \% or FEV $1 \%<70 \%$ of the predicted value. ${ }^{\mathrm{a}} \mathrm{P}<0.05$, comparation between the $\mathrm{PEEP} \mathrm{EIT}_{\mathrm{T}}$ and $\mathrm{PEEP} \mathrm{P}_{5}$ in the normal subgroup. ${ }^{\mathrm{b}} \mathrm{P}<0.05$, comparation between the $\mathrm{PEEP}_{\mathrm{EIT}}$ and $\mathrm{PEEP}_{5}$ in the poor lung function subgroup. 
Table 3 Subgroup analyses of the changes in respiratory mechanics and $\mathrm{PaO}_{2} / \mathrm{FiO}_{2}$ in patients with right or left lung ventilation under different PEEP levels

\begin{tabular}{|c|c|c|c|c|c|c|}
\hline Ventilated side & Group & $n$ & DLV & OLV $0.5 \mathrm{~h}$ & OLV $1 \mathrm{~h}$ & DLV- ${ }_{\text {End of operation }}$ \\
\hline \multirow[t]{2}{*}{ Right } & PEEP $_{5}$ & 18 & $314.0+112.1$ & $208.7+92.0$ & $232.3+88.9$ & $368.7+133.2$ \\
\hline & PEEP $P_{E I T}$ & 15 & $389.8+75.9$ & $274.1+119.9^{a}$ & $336.0+106.2^{a}$ & $476.4+113.3^{a}$ \\
\hline \multirow[t]{2}{*}{ Left } & PEEP $_{5}$ & 35 & $329.0+112.1$ & $182.3+75.0$ & $212.9+63.5$ & $322.7+123.5$ \\
\hline & PEEP $P_{\text {EIT }}$ & 32 & $343.5+101.3$ & $243.9+99.6^{b}$ & $302.9+98.5^{b}$ & $433.2+137.2^{b}$ \\
\hline \multirow[t]{2}{*}{ Right } & PEEP $_{5}$ & 18 & $24.0+5.5$ & $14.9+3.8$ & $16.1+4.6$ & $24.7+6.1$ \\
\hline & PEEP $_{\text {EIT }}$ & 15 & $28.2+7.8$ & $19.7+5.9^{a}$ & $20.8+7.3^{\mathrm{a}}$ & $27.9+8.0$ \\
\hline \multirow[t]{2}{*}{ Left } & $\mathrm{PEEP}_{5}$ & 35 & $27.3+7.2$ & $14.1+2.8$ & $15.4+2.6$ & $27.3+7.7$ \\
\hline & PEEP $_{\text {EIT }}$ & 32 & $24.4+5.6$ & $17.9+5.5^{\mathrm{b}}$ & $19.9+6.7^{b}$ & $26.1+5.9$ \\
\hline Right & PEEP $_{\text {EIT }}$ & 15 & $14.3+5.0$ & $16.5+4.2^{\mathrm{a}}$ & $16.7+4.1^{\mathrm{a}}$ & $14.6+4.5$ \\
\hline \multirow[t]{2}{*}{ Left } & PEEP $_{5}$ & 35 & $14.7+3.1$ & $18.2+3.8$ & $19.1+3.5$ & $14.7+3.0$ \\
\hline & PEEP $_{\text {EIT }}$ & 32 & $13.1+3.7$ & $14.0+2.4^{\mathrm{b}}$ & $13.5+2.3^{b}$ & $13.7+3.5$ \\
\hline
\end{tabular}

${ }^{\mathrm{a}}, \mathrm{P}<0.05$, comparation between the $\mathrm{PEEP}_{\mathrm{EIT}}$ and $\mathrm{PEEP}_{5}$ in the right lung ventilation subgroup; ${ }^{\mathrm{b}}, \mathrm{P}<0.05$, comparation between the $\mathrm{PEEP} \mathrm{EIT}$ and $\mathrm{PEEP}_{5}$ in the left lung ventilation subgroup.

Table 4 Comparison of respiratory dynamic, arterial blood gas and haemodynamic parameters between the PEEP 5 and $\mathrm{PEEP}_{\mathrm{EIT}}$ groups at different time points

\begin{tabular}{|c|c|c|c|c|c|}
\hline Parameters & Group & DLV & OLV $0.5 \mathrm{~h}$ & OLV $1 \mathrm{~h}$ & DLV-End of operation \\
\hline \multicolumn{6}{|c|}{ Respiratory dynamic parameters } \\
\hline \multirow[t]{2}{*}{$\mathrm{P}_{\text {peak }}\left(\mathrm{cmH}_{2} \mathrm{O}\right)$} & PEEP $_{5}$ & $21.7 \pm 2.8$ & $25.5 \pm 4.0$ & $25.7 \pm 3.8$ & $22.2 \pm 2.9$ \\
\hline & PEEP $_{E I T}$ & $20.7 \pm 4.1$ & $27.6 \pm 3.8^{*}$ & $27.7 \pm 4.6^{*}$ & $21.2 \pm 3.8$ \\
\hline $\mathrm{P}_{\text {plat }}\left(\mathrm{cmH}_{2} \mathrm{O}\right)$ & PEEP $_{5}$ & $19.6 \pm 2.9$ & $23.5 \pm 3.8$ & $23.7 \pm 3.7$ & $20.2 \pm 2.9$ \\
\hline $\mathrm{P}_{\text {mean }}\left(\mathrm{cmH}_{2} \mathrm{O}\right)$ & PEEP $_{\text {EIT }}$ & $10.5 \pm 3.5$ & $14.4 \pm 2.8^{*}$ & $13.4 \pm 2.3^{*}$ & $11.7 \pm 2.7$ \\
\hline \multicolumn{6}{|c|}{ Arterial blood gas analysis parameters } \\
\hline \multirow[t]{2}{*}{$\mathrm{pH}$} & $\mathrm{PEEP}_{5}$ & $7.38 \pm 0.05$ & $7.36 \pm 0.04$ & $7.37 \pm 0.04$ & $7.37 \pm 0.06$ \\
\hline & PEEP $_{\text {EIT }}$ & $7.39 \pm 0.05$ & $7.32 \pm 0.42$ & $7.38 \pm 0.05$ & $7.41 \pm 0.05^{*}$ \\
\hline \multicolumn{6}{|c|}{ Haemodynamic parameter } \\
\hline \multirow[t]{2}{*}{ MAP (mmHg) } & $\mathrm{PEEP}_{5}$ & $81.2 \pm 14.3$ & $76.9 \pm 12.9$ & $75.8 \pm 13.0$ & $86.1 \pm 15.3$ \\
\hline & PEEP $P_{E I T}$ & $76.6 \pm 11.7$ & $76.8 \pm 16.3$ & $79.4 \pm 15.3$ & $85.8 \pm 12.8$ \\
\hline
\end{tabular}

$P_{\text {peak }}$, airway peak pressure; $P_{\text {plat }}$, Platform pressure; $P_{\text {mean }}$, mean airway pressure; $\mathrm{PaCO}_{2}$, partial pressure of carbon dioxide in artery; MAP, mean arterial blood pressure; compared with the $P E E P_{5}$ group, ${ }^{*} P<0.05$. 
Table 5 Comparison of vasopressin drug use, lung complications and lengths of hospital stay between the $\mathrm{PEEP}_{5}$ and $\mathrm{PEEP}_{\mathrm{EIT}}$ groups

\begin{tabular}{lccc}
\hline Group & $\begin{array}{c}\text { Vasopressor } \\
\text { (yes/no) }\end{array}$ & $\begin{array}{c}\text { Lung complications } \\
\text { (yes/no) }\end{array}$ & $\begin{array}{c}\text { Hospital stay } \\
\text { (days) }\end{array}$ \\
\hline PEEP $_{5}$ & $21 / 29(42 \%)$ & $17 / 50(34 \%)$ & $5.33 \pm 2.13$ \\
PEEP $_{\text {EIT }}$ & $24 / 26(48 \%)$ & $15 / 50(30 \%)$ & $6.00 \pm 2.97$ \\
$P$ & 0.55 & 0.67 & 0.21 \\
\hline
\end{tabular}

ventilation. Oxygenation-based methods require multiple arterial blood gas samples, which might not be suitable for clinical use. All the methods use global measures that might not reflect the regional pulmonary status (22).

In the present study, an EIT-based PEEP optimization method was applied, which utilized the regional information on the lung ventilation. The PEEP value determined by EIT titration for the studied elderly patients was significantly higher than the PEEP value used for the fixed PEEP ventilation group. Compared with the fixed PEEP ventilation group, the individualized PEEP ventilation group exhibited significantly increased oxygenation index values during and after the operation, increased $\mathrm{C}_{\mathrm{dyn}}$ values and reduced driving pressures. This result is consistent with the results reported by Pereira et al. in a study involving patients who underwent laparoscopy (9). Pereira et al. found that respiratory compliance in the study group was higher than that in the control group with a PEEP of $4 \mathrm{cmH}_{2} \mathrm{O}$ (9). The use of the PEEP method was independent of oxygenation. The main mechanism of improving oxygenation by PEEP is the reduction of the right-to-left pulmonary shunt by keeping the alveolar open $(23,24)$. The PEEP method not only restores alveolar expansion, but also affects every lung unit involved in ventilation by influencing the driving pressure. In patients with sufficient muscle relaxation, the driving pressure can better reflect the alveolar pressure. Some studies have shown that a lower driving pressure correlates with the long-term prognosis of patients and may improve the survival rate of patients with ARDS (25). Although most of the previous findings are related to ARDS, Karagiannidis et al. reported that EIT-based determination of the PEEP setting can improve the homogeneity of ventilation in chronic obstructive pulmonary disease (COPD) patients (26). This might be one of the underlying mechanisms of improved respiratory mechanics and gas exchange.

One risk of PEEP titration is that the applied high airway pressures may affect the stability of the circulatory system. Previous animal studies have suggested that higher PEEP values reduce the volume of blood returning to the heart and increase the incidence of hypotension and vasoactive drug usage (27). One possible reason for these findings is that the high PEEP $\left(20 \mathrm{cmH}_{2} \mathrm{O}\right)$ used in those experiments, may have increased the intrathoracic pressure and reduced the venous return. In the present study, continuous injection of norepinephrine was not required in either the control or EIT group. There was no significant difference in vasoactive drug usage between the two groups during the operation. Ferrando et al. (28) also found that the haemodynamics were stable under different PEEP values and that the PEEP had no effect on the surgery. We found that the $\mathrm{P}_{\text {peak }}$ in the EIT group was higher than that in the control group, which is due to a much higher PEEP in the EIT group. The procedure was terminated early for a total of 4 patients, who were in the EIT group, due to the combination of $\mathrm{P}_{\text {peak }}>$ $40 \mathrm{cmH}_{2} \mathrm{O}$ and hypoxia or haemodynamic instability during the operation (Figure 1). The reason for this result may be that a high PEEP affects the amount of venous blood in this part of the patients, resulting in a decrease in blood pressure and oxygen saturation. This result suggests that when we use PEEP values determined by EIT titration, close monitoring of the $\mathrm{P}_{\text {peak }}$, oxygenation and haemodynamic is strongly recommended. In the follow-up phase, these patients had no complications, and the lengths of hospital stay were in the normal range.

Another issue regarding PEEP titration is the extension of the operation time. Considering all the advantages that individualized PEEP may potentially offer (e.g., the prevention of alveolar collapse in the dependent lung in the lateral posture, increase in the residual volume, an improvement in the ventilation/perfusion ratio, a reduction of the shear damage caused by periodic opening and closing of the alveoli), the small extension of the operation ( 10 minutes) time should be acceptable. The increase in ventilating volume will affect the alveolar carbon dioxide gas exchange. The results showed that $\mathrm{PaCO}_{2}$ in the EIT group was lower than that in the control group, suggesting that the patients in the EIT group had a better alveolar ventilation status. The increase in $\mathrm{PaCO}_{2}$ led to an increase in blood hydrogen ion concentration and a decrease in $\mathrm{pH}$ (Table 4).

No differences were found in postoperative pulmonary complications or length of hospital stay (Table 5). Since 
the sample size calculation was based on the primary endpoints, a larger randomized controlled trial should be conducted in the future, providing reliable data on the possible differences in complication rates and hospital stay that were not found in the present study. In thoracic surgery, $100 \%$ oxygen concentration is recommended to prevent and treat hypoxemia during OLV, but prolonged exposure to high oxygen levels may lead to lung injury (29). One of the limitations is that the effects of prolonged 1.0 $\mathrm{FiO}_{2}$ and higher $\mathrm{P}_{\text {peak }}$ in the EIT group compared with the control group on the long-term outcomes were not studied. A high oxygen fraction is considered to increase the risk of atelectasis. However, we chose $1.0 \mathrm{FiO}_{2}$ to ensure oxygenation during OLV, as we were uncertain whether it would cause hypoxia when we used a different PEEP and a lower $\mathrm{FiO}_{2}$. Before closing the chest, we performed the recruitment manoeuvre with a $\mathrm{FiO}_{2}$ of 0.6 to prevent atelectasis. Among the 100 study patients, 11 had atelectasis after the operation, including 6 in the $\mathrm{PEEP}_{5}$ group and 5 in the PEEP EIT $_{\text {group. How individualized PEEP values }}$ might change when the oxygen concentration is reduced is also worth investigating in future studies. Ventilation distribution was not monitored in the $\mathrm{PEEP}_{5}$ group, so a comparison of ventilation heterogeneity was not possible. Nevertheless, we were able to demonstrate the differences in lung mechanics and oxygenation between the two groups, which were the primary and secondary endpoints of the study. Since a fixed PEEP is still widely used, we compared it with the EIT method in the current study to confirm the necessity of individualized PEEP titration. A comparison of this individualized method with other PEEP titration methods would be interesting for future studies.

\section{Conclusions}

Individualized PEEP values determined by EIT titration can improve ventilation and respiratory mechanics in elderly patients undergoing thoracoscopic surgery during OLV.

\section{Acknowledgments}

Many thanks to Dr. Qiliang Jiang for all the suggestions and help for this study.

Funding: This work was supported by the National Natural Science Foundation of China [81671078 to J Wu]; Shanghai Municipal Science and Technology Committee [16411967600 to J Wu]; and Shanghai Municipal
Commission of Health and Family Planning Project [201840319 to J Wu].

\section{Footnote}

Conflicts of Interest: Zhanqi Zhao receives a consulting fee from Dräger Medical. Inéz Frerichs receives funding from the European Union's 7th Framework Programme for Research and Technological Development (WELCOME, Grant No. 611223) and the European Union's Framework Programme for Research and Innovation Horizon 2020 (CRADL, Grant No. 668259, WELMO, Grant 825572) and reimbursements for speaking fees, conference costs and travel costs from Dräger Medical. The other authors have no conflicts of interest to disclose.

Ethical Statement: The authors are accountable for all aspects of the work in ensuring that questions related to the accuracy or integrity of any part of the work are appropriately investigated and resolved. This study was approved by the Ethics committee of the Shanghai Chest Hospital (Chairman: Dr. Zheng Ning, permission NO. KS1866) on Sep-18-2018, and all patients signed written informed consent forms before enrolment. The trial was registered in the Chinese Clinical Trial Registry, which is available at www.chictr.org.cn/ with, registry number: ChiCTR1900021119, on Jan-29-2019.

\section{References}

1. Yutaka Y, Sonobe M, Kawaguchi A, et al. Prognostic impact of preoperative comorbidities in geriatric patients with early-stage lung cancer: Significance of sublobar resection as a compromise procedure. Lung Cancer 2018;125:192-7.

2. Wang S, Li X, Li Y, et al. The long-term impact of postoperative pulmonary complications after video-assisted thoracic surgery lobectomy for lung cancer. J Thorac Dis 2017;9:5143-52.

3. Cattaneo SM, Park BJ, Wilton AS, et al. Use of videoassisted thoracic surgery for lobectomy in the elderly results in fewer complications. Ann Thorac Surg 2008;85:231-5; discussion 235-6.

4. Lugg ST, Agostini PJ, Tikka T, et al. Long-term impact of developing a postoperative pulmonary complication after lung surgery. Thorax 2016;71:171-6.

5. Agostini PJ, Lugg ST, Adams K, et al. Risk factors and short-term outcomes of postoperative pulmonary 
complications after VATS lobectomy. J Cardiothorac Surg 2018;13:28.

6. Yang J, Xia Y, Yang Y, et al. Risk factors for major adverse events of video-assisted thoracic surgery lobectomy for lung cancer. Int J Med Sci 2014;11:863-9.

7. Schultz MJ, Abreu MG, Pelosi P. Mechanical ventilation strategies for the surgical patient. Curr Opin Crit Care 2015;21:351-7.

8. Güldner A, Kiss T, Serpa Neto A, et al. Intraoperative protective mechanical ventilation for prevention of postoperative pulmonary complications: a comprehensive review of the role of tidal volume, positive end-expiratory pressure, and lung recruitment maneuvers. Anesthesiology 2015;123:692-713.

9. Pereira SM, Tucci MR, Morais CCA, et al. Individual Positive End-expiratory Pressure Settings Optimize Intraoperative Mechanical Ventilation and Reduce Postoperative Atelectasis. Anesthesiology 2018;129:1070-81.

10. Zhang BJ, Tian HT, Li HO, et al. The effects of onelung ventilation mode on lung function in elderly patients undergoing esophageal cancer surgery. Medicine (Baltimore) 2018;97:e9500.

11. Futier E, Jaber S. Lung-protective ventilation in abdominal surgery. Curr Opin Crit Care 2014;20:426-30.

12. Blank RS, Colquhoun DA, Durieux ME, et al. Management of One-lung Ventilation: Impact of Tidal Volume on Complications after Thoracic Surgery. Anesthesiology 2016;124:1286-95.

13. Frerichs I, Amato MB, van Kaam AH, et al. Chest electrical impedance tomography examination, data analysis, terminology, clinical use and recommendations: consensus statement of the TRanslational EIT developmeNt stuDy group. Thorax 2017;72:83-93.

14. Hinz J, Gehoff A, Moerer O, et al. Regional filling characteristics of the lungs in mechanically ventilated patients with acute lung injury. Eur J Anaesthesiol 2007;24:414-24.

15. Nestler C, Simon P, Petroff D, et al. Individualized positive end-expiratory pressure in obese patients during general anaesthesia: a randomized controlled clinical trial using electrical impedance tomography. Br J Anaesth 2017;119:1194-205.

16. Costa EL, Borges JB, Melo A, et al. Bedside estimation of recruitable alveolar collapse and hyperdistension by electrical impedance tomography. Intensive Care Med 2009;35:1132-7.

17. Zhao Z, Wang W, Zhang Z, et al. Influence of tidal volume and positive end-expiratory pressure on ventilation distribution and oxygenation during one-lung ventilation. Physiol Meas 2018;39:034003.

18. Kalil AC, Metersky ML, Klompas M, et al. Executive Summary: Management of Adults With Hospital-acquired and Ventilator-associated Pneumonia: 2016 Clinical Practice Guidelines by the Infectious Diseases Society of America and the American Thoracic Society. Clin Infect Dis 2016;63:575-82.

19. Kogan A, Segel MJ, Ram E, et al. Acute Respiratory Distress Syndrome following Cardiac Surgery: Comparison of the American-European Consensus Conference Definition versus the Berlin Definition. Respiration 2019;97:518-24.

20. Grichnik KP, Shaw A. Update on one-lung ventilation: the use of continuous positive airway pressure ventilation and positive end-expiratory pressure ventilation--clinical application. Curr Opin Anaesthesiol 2009;22:23-30.

21. Leong LM, Chatterjee S, Gao F. The effect of positive end expiratory pressure on the respiratory profile during one-lung ventilation for thoracotomy. Anaesthesia 2007;62:23-6.

22. Frerichs I, Dargaville PA, Rimensberger PC. Regional respiratory inflation and deflation pressure-volume curves determined by electrical impedance tomography. Physiol Meas 2013;34:567-77.

23. Ranieri VM, Mascia L, Fiore T, et al. Cardiorespiratory effects of positive end-expiratory pressure during progressive tidal volume reduction (permissive hypercapnia) in patients with acute respiratory distress syndrome. Anesthesiology 1995;83:710-20.

24. Gattinoni L, Collino F, Maiolo G, et al. Positive endexpiratory pressure: how to set it at the individual level. Ann Transl Med 2017;5:288.

25. Toufen Junior C, De Santis Santiago RR, Hirota AS, et al. Driving pressure and long-term outcomes in moderate/ severe acute respiratory distress syndrome. Ann Intensive Care 2018;8:119.

26. Karagiannidis C, Waldmann AD, Roka PL, et al. Regional expiratory time constants in severe respiratory failure estimated by electrical impedance tomography: a feasibility study. Crit Care 2018;22:221. 
27. Algera AG, Pisani L, Chaves RCF, et al. Effects of peep on lung injury, pulmonary function, systemic circulation and mortality in animals with uninjured lungs-a systematic review. Ann Transl Med 2018;6:25.

28. Ferrando C, Soro M, Unzueta C, et al. Individualised perioperative open-lung approach versus standard protective ventilation in abdominal surgery (iPROVE): a randomised controlled trial. Lancet Respir Med 2018;6:193-203.

29. Sugahara K, Tokumine J, Teruya K, et al. Alveolar epithelial cells: differentiation and lung injury. Respirology 2006;11 Suppl:S28-31.

Cite this article as: Liu $\mathrm{K}$, Huang $\mathrm{C}, \mathrm{Xu} \mathrm{M}, \mathrm{Wu} \mathrm{J}$, Frerichs I, Moeller K, Zhao Z. PEEP guided by electrical impedance tomography during one-lung ventilation in elderly patients undergoing thoracoscopic surgery. Ann Transl Med 2019;7(23):757. doi: 10.21037/atm.2019.11.95 